\title{
The gamification of education and business: a critical analysis and future research prospects
}

\author{
Amy DuVernet, Alberto Asquer and Inna Krachkovskaya
}

Gamification can be defined as the application of gaming mechanics, such as points or achievements, in non-game contexts (Deterding et al., 2011a; 2011b). By applying gaming elements in such contexts, users' motivation and subsequent behaviors are directed toward desirable user-machine interactions. While the term's origins date back to the early 2000s (Werbach and Hunter, 2012), gamification did not gain widespread attention within professional and academic circles until close to a decade later, when it became apparent that game principles and techniques were growing increasingly popular in various social, academic and professional settings; the term first appeared in Google trend indexing in late 2010 (Google, 2015). The following year, Gartner, a research and advisory firm, predicted that over 70 percent of Global 2000 organizations would incorporate gamification in at least one process by the year 2014 (Gartner, 2011) and Markets and Markets, a market research firm, forecast that the gamification market would total $\$ 5.5$ billion annually by 2018 (2011). However, the next year brought a more dismal outlook, with Gartner predicting that 80 percent of gamified applications would flounder by 2014, failing to meet the business goals for which they were developed. While research into the effectiveness of gamification in meeting business and societal goals has produced mixed findings (for example, Domínguez et al., 2013), the method has clearly maintained popularity; in 2014, Training Industry, Inc., a market intelligence firm, estimated the revenue for gamification-related training services to be $\$ 274$ million globally (Training Industry, Inc., 2015).

Further evidence comes from the plethora of gamification examples found in business, educational and social settings. For example, it is not uncommon to find gaming elements incorporated into popular social networking applications (for example, Facebook, LinkedIn, Twitter). Moreover, gamification has been applied in academic settings ranging from pre-kindergarten through post-baccalaureate education (Caponetto et al., 2014).

Common workplace contexts in which gamification has been used include organizational training and development initiatives, employee selection programs and employee engagement programs (DuVernet and Popp, 2014).

Gamification has received mixed reviews; while some enthusiastically extol its value as a fresh approach to stimulating individuals' creativity, learning and other productive 
behaviors (for example, Burke, 2013; 2014), others criticize the technique, highlighting the potential for exploitation (for example, Bogost, 2011) and mixed results related to its effectiveness. The growth of consumer electronics in daily life and the increasing amount of time that individuals devote to various forms of game-like interaction on digital devices, such as tablets and smartphones, suggests that the role of gamification should not be so easily dismissed as a temporary fad. Rather, gamification must be considered seriously by both academics and practitioners as a way to gain insights into the nature of human-computer interaction and, more generally, into the transformative effects of the growing presence of digital artifacts in society.

This chapter aims to critically assess gamification in an era of digital transformation, placing it in the contexts of both academic research and practical applications. The chapter begins with a delineation of the concept, providing detail on the defining elements of gamification. This is followed by a summary of the ways in which gamification has been applied in educational and business settings and the empirical work investigating its impact. In summarizing this work, we also review critical arguments and extant questions inherent in the use of gamification. Finally, we outline a research agenda for clarifying the controversial aspects of gamification and addressing criticisms of the technique.

\section{GAMIFICATION: DEFINITION AND DELINEATION}

The field of gamification has suffered from a lack of consensus on the definition of its core concept (Deterding et al., 2011a; Fuchs et al., 2014; Hamari et al., 2014; Walz and Deterding 2014; Seaborn and Fels, 2015). Some definitions limit gamification to digital applications of gaming mechanics (for example, Domínguez et al., 2013), while others argue that this definition is too narrow (for example, DuVernet, in press). We believe that non-digital systems can be gamified; however, for the purposes of this chapter, we focus specifically on digital instances of gamification in line with the purposes of the volume.

Moreover, we concur with previous works (DuVernet and Popp, 2014; Kapp, 2014), which point to features that distinguish gamification from other similar concepts (for example, serious games and simulations). These features include the time interval in which gamification operates, the users' experience, and the purposes or desired outcomes of the technique. Gamified contexts typically influence behavior through the cultivation of longterm user engagement; in contrast, games and simulations usually include a clear beginning and end. Users are generally cognizant of their participation in games and simulations while gamification elements are generally less salient to users, acting as enhancements to the 
context with which they are interacting. Finally, while gamification is typically layered over an existing program or context as a motivational mechanism to encourage user participation, games and simulation often act as the primary purpose for engagement.

The types of gaming elements applied to non-game contexts vary across individual initiatives, purposes and programs. Elements that are commonly transported from traditional games to non-game digital contexts include levels, badges, points, progress bars, leader boards, narrative quests and virtual goods. Table 16.1 defines each; for a more extensive review see Hsu et al.'s (2013) hierarchical framework of 35 gamification features. Each of these elements and features serve to guide user behavior through various motivational mechanisms including goal setting, the provision of performance feedback, achievement recognition, and both social facilitation and competition (Muntean, 2011).

\section{<INSERT TABLE 16.1 ABOUT HERE>}

\section{MECHANISMS OF INFLUENCE}

Several motivational theories provide a helpful lens through which the impact of gamification on behavior can be interpreted. Within the frame of these theories, gamification acts to modify user attitudes and behaviors through a number of psychological mechanisms including goal setting, intrinsic motivation, competition and social collaboration. Each of the aforementioned gaming elements provide feedback, recognition of achievement, and indications of status, creating competition amongst users and/or encouraging cooperation and social collaboration. For example, points provide immediate feedback to users on their performance by rewarding the user when they perform certain desired behaviors or activities. The combination of points and leaderboards creates a competitive environment, making users' relative standing within groups or across the population of users salient. Similarly, badges offer performance feedback and encourage social comparisons and competition; users are able to view others' badges by reviewing their user information or profiles and displaying their own achievements in this way. Further, badges, points and leaderboards enact a goalsetting mechanism. By providing explicit or implicit details about the activities or tasks that will result in rewards these elements serve to direct user attention to clear, specific and difficult goals, enacting powerful motivational tools to drive user activity. In line with this, recent research indicates that the mere presence of a leaderboard results in user behavior, goal setting and goal commitment outcomes equivalent to those observed with classic, explicit goal-setting initiatives (Landers et al., 2015). 
Level and narrative gamification elements also serve to stimulate goal-setting behaviors by directing users' attention and behaviors to specific tasks necessary to complete a level or progress through the storyline. By creating subgoals that move users through progressively more difficult levels or storyline milestones, these elements serve to direct attention towards desired activities, successively build skills, and foster self-efficacy for activity completion by users (Papastergiou, 2009; Lu et al., 2012; Perryer et al., 2012; Popescu et al., 2012). Moreover, much research has demonstrated the significant, positive relationships between self-efficacy for task success and both motivation to complete the task and performance within the task (Mitchell and Daniels, 2003); thus by positively impacting user self-efficacy, gamified contexts motivate continued interaction. Finally, while leaderboards and badges tend to enact competitive, social comparison mechanisms, virtual goods tend to encourage collaboration; by incorporating this element, gamified contexts allow users to interact, barter trades, and work toward common goals in a communal fashion.

It is also important to consider the type of motivation that these elements instill. Extrinsic motivation is driven by external factors and rewards, whereas intrinsic motivation is driven primarily by the inherent value of completing a task, in and of itself (Staw, 1976). Research has shown that the provision of external rewards can strengthen extrinsic motivation at the expense of intrinsic motivation (Mitchell and Daniels, 2003). As manifestations of accomplishments, visible rewards, such as points, virtual goods, and badges, may serve as extrinsic motivators (Antin and Churchill, 2011; Fox and Bailenson, 2009; Hershfield et al., 2011; Yee et al., 2009), but fall short of creating sustained effort (Mekler et al., 2013) because they in turn reduce users' intrinsic motivation for engaging with the system. Much work has demonstrated the superiority of intrinsic rewards over extrinsic rewards in terms of motivating long-term behavior (Deci, 1975; Deci et al., 1999; Deci and Ryan, 2000; Ryan and Deci, 2000). Thus, the most common features of gamification (for example, points, badges and leaderboards) may not suffice as meaningful long-term motivators (Deterding, 2012; McGonigal, 2011; Mekler et al., 2013). Some evidence has shown that both user enjoyment and desired outcomes (for example, user behaviors, engagement) decline with use and interaction with gamified scenarios (Koivisto and Hamari, 2014).

Still, the relationship between internal and external sources of motivation to engage in gamified contexts deserves additional attention. Fleming (2012) suggests that the two types of rewards interact in a more articulated way: extrinsic rewards can stimulate the formation of intrinsically oriented sources of motivation, especially when receiving an extrinsic reward 
for an achievement also carries a significant symbolic meaning for the recipient. Deterding et al. (2011b) suggested that games should provide 'situated motivational affordances', wherein game-like features enhance motivation through their addition to activities that are already intrinsically valuable for participants. If sources of motivation are properly understood, gamification design can include inducements to amplify existing 'signals' (that is, genuine intrinsic interest) into sustained attention and energy toward desired activities within the system (Paharia, 2012b; Watson, 2014).

Yet another theoretical frame from which to view the impact of gamification is that of Csikszentmihalyi's (2008) 'flow theory', which holds that individuals experience optimal work 'flow' when they are involved in activities that provide an adequate balance between challenge and skill. Excessively difficult challenges induce frustration and activity abandonment. Activities that present an inadequate challenge with respect to individual skill and ability levels can lead to disinterest and abandonment as well. A gamified system can activate a 'flow' experience in users when the content, layering of elements, mode and style are carefully designed to create an optimal balance between ease and difficulty.

\section{APPLICATIONS IN THE REAL WORLD}

Regardless of the mechanisms through which gamification impacts user behavior, it's clear that digital enterprise systems are increasingly incorporating this technique into user interfaces. Research conducted by Hamari and Koivisto (2015a) points to the major purposes for which gamification services are typically used, including increased utility and ease of use, amplified user enjoyment and playfulness, and to a lesser extent, greater recognition and social influence. Gamification has been applied in academic, corporate and commercial settings to achieve each of these purposes.

\section{Educational Applications of Gamification}

The use of gamification in educational settings has grown considerably, as evidenced by the rise in published literature citing its use in academic settings, from 206 in 2011 to 1,620 studies in 2013 (Caponetto et al., 2014). While numerous works suggest that it can result in positive effects on learners' motivation and performance (for example, Caponetto et al., 2014; Domínguez et al., 2013; Hamari et al., 2014; Rouse, 2013), the literature is still unclear in terms of when and how exactly gamification exerts a positive influence on academic performance and learning. Sung and Hwang (2013), for example, found that a collaborative educational game benefited students in promoting learning attitudes and motivation, and in 
improving their learning achievements and self-efficacy. Further research has shown that gamification can support learning through the provision of both immediate and delayed feedback (Crookall, 2010; Perryer et al., 2012; Popescu et al., 2012). Domínguez et al. (2013), however, provides a more tempered view: while students exposed to gamified experiences performed better on practical assignments, their performance on written assignments and their participation in class activities suffered.

Thus, while gamification seems functional in motivating student learning efforts and fueling additional sources of interest towards the subjects studied, additional research work is needed to specify how precisely gamified learning should be designed and implemented. For example, Landers and Landers (2014) suggest certain conditions must be met in order for gamification to enhance course performance, including the provision of time-bound leaderboard tasks that are specific, measurable and realistically achievable. More work is needed to parcel out the impact of these conditions to identify best practices for the design and application of gamification in educational settings.

\section{Gamification in the Workplace}

Within workplace settings, gamification has been predominantly applied in employee training, selection, incentive and engagement programs. Examples of the gamification of these employee processes are detailed below.

\section{Gamification in training}

Perhaps the most popular application of gamification in the workplace has been in corporate training and development. For example, research conducted at Training Industry, Inc. points to the growing popularity of gamification in learning and development initiatives. From 2012 to 2013 , organizations using gamification within sales training grew from approximately 8 percent to approximately 18 percent (Taylor, 2014). Even more evidence for the common use of gamification in training initiatives came in 2015, when Training Industry, Inc. reported that approximately 37 percent of organizations had embedded or were planning to embed gamification in their learning management systems (LMS) and 36 percent were using or planning to use gamification in training content. Thus, it is clear that gamification has become a common application in corporate learning and development programs.

These numbers are not surprising; gamification is purported to make learning fun and increase learner motivation and accountability. Further, e-learning has become quite prevalent within training and development initiatives, making it convenient and feasible to 
supplement learning contexts with gaming elements that are dependent on technology. These elements serve to encourage participation and interaction in virtual training by rewarding points or badges to learners based on their interactions with each other, the instructor or the platform. Learners progress through hierarchical levels and are awarded points or badges to designate the completion of learning milestones, such as specific modules and sessions, or the successful demonstration of learned skills or knowledge.

As in the educational space, the popularity of gamification contrasts with mixed empirical results regarding its impact on corporate learning and development outcomes. While some research has indicated that gamification can lead to improved learner reactions (that is, affective experiences including satisfaction and perceived utility of training; Taylor, 2014), and both engagement and motivation to complete and apply training on the job (Dong et al., 2012; Downes-LeGuin et al., 2012; Landers and Callan, 2011), other research provides more tempered results pointing to both context and individual differences as moderators of those relationships (for example, Armstrong and Landers, 2015). Case examples, however, emphasize performance, learning and motivational improvements. For example, Kapp (2014) reports a 45 percent reduction in safety incidents and claims following the introduction of gamification into Pep Boys' training program.

Thus, while the gamification of corporate learning initiatives has, arguably, received the greatest attention within the research literature, this line of inquiry remains an emerging topic with numerous unresolved questions. More work is needed to expand our understanding of gamification in corporate training.

\section{Gamification in employee selection}

Employee recruitment and selection systems have also begun utilizing gamification (Meister, 2012). Organizations have implemented points and other rewards in their recruitment systems to encourage both referral and applicant activities (for example, employee sharing of job postings, exploration of job openings, completion of interest forms, viewing a realistic job preview video; DuVernet and Popp, 2014). An example can be found in the United States Army multi-player game, wherein potential army recruits are able to experience a soldier's responsibilities by engaging in an informative and entertaining game. By providing realistic information about the job of a soldier in an entertaining format, the US Army allows potential candidates to self-select into the role based on their experiences and is able to identify applicants who exhibit exceptional skills relevant to the job (Fetzer, 2015). 
Organizations are also beginning to consider how to apply gamification in employee selection assessments (that is, evaluations of relevant knowledge, skills, abilities and other characteristics used to identify candidates with the highest probability of successful job performance). These assessments can include gaming content elements such as interactive or branching media-based items, simulations or problem solving. Because this approach is in its infancy, test-developers must use caution, focusing on introducing specific, controllable game-like aspects to assessments one at a time (Handler, 2014).

\section{Other workplace gamification initiatives}

Gamification has been used as an element in employee incentive programs as well. These types of programs have been used to increase the performance motivation of both sales and customer service employees, leading to increased revenue and customer satisfaction (Bunchball, Inc., 2012). Further, research points to additional positive workplace outcomes, including reduced employee stress (Perryer et al., 2012), sustained social capital (Zhu et al., 2013), and increased employee loyalty (Dorling and McCaffery, 2012). Thus, it is evident that a sizeable portion of organizational programs have been subjected to some form of gamification, and this trend is likely to continue.

\section{Consumer-Facing Applications}

Beyond workplace and academic applications, gamification has also been used to incentivize participation in market research, social networking sites and consumer applications. In 2015, the GreenBook Research Industry Trends Report indicated that 21 percent of market research organizations were utilizing some form of gamification and an additional 35 percent were considering it. This represented a large increase from the 15 percent of organizations using gamification for market research in 2013.

Further, gamification has become a common mechanism for engagement across popular websites and applications. For example, the professional networking platform LinkedIn has incorporated multiple gaming elements (for example, progress bars, badges, social endorsements and leaderboards rankings) to increase user activity, interaction, and to become a more entrenched application for professional needs. Other popular consumer services such as the health and fitness applications found in FitBit, Nike+, and Apple's iWatch applications utilize gaming elements to increase user engagement by displaying dashboards with visual representations of fitness achievements such as badges, points and leaderboard rankings. Research conducted by Hamari and Koivisto (2015b) provides 
empirical evidence for the impact of such techniques; gamification induced a greater willingness to work out via social influence, positive recognition and reciprocity mechanisms. Further examples of gamification utilize the technique in common reward and social referral programs, such as Foursquare and My Starbucks Rewards, to engage consumers and increase brand loyalty and product use.

\section{CRITICAL PERSPECTIVES ON GAMIFICATION}

The rise and popularity of gamification has fostered contrasting views within the scholarly and applied communities. The opportunity to employ digital technologies in this way unleashed a proliferation of enthusiastic consultants and software developers eager to promote this technique as an enhancement to various managerial and marketing issues. To many, however, the buzz generated by gamification obfuscated the actual function of gamification, hampering a thorough investigation and purposeful application of gamification for desired outcomes. Setting the hype aside, a balanced approach and interpretation of gamification is warranted. Gamification will generally not act as a 'quick fix' for organizations seeking to boost employee morale and productivity, attract and retain customers, or otherwise positively impact digital engagement goals (Juul, 2011; Robson et al., 2015). Various criticisms aimed at this technique must be considered before choosing to implement gamification in practice. Below, we summarize three main themes of such criticisms, including the foundations of gamification in motivational theory, the potential for deception and exploitation in the use of this technique, and data privacy concerns.

A major critique of gamification targets its presumed motivational effects. Motivating individuals and groups to engage in certain desired tasks and behaviors is central to the purpose of gamification. Yet the relationship between the introduction of game-like features and both motivation to complete activities and actual behaviors is not straightforward. Much of the literature around gamification posits claims that oversimplify the complex interaction between a game setting and individual personality, attitudes and behavioral drivers. The foundation of gamification in motivational theory is often overlooked in the research literature and, as previously mentioned, its impact on intrinsic and extrinsic motivation remains unclear. Further, the impact of gamification on desired outcomes has often been studied under less than rigorous experimental conditions, leading to questions surrounding the conclusions drawn in much of the extant empirical literature (Hamari et al., 2014; Lieberoth, 2015). This concern and the possible avenues for addressing it are discussed in the following section. 
Another critique emerging in the gamification literature relates to the ethical and moral implications of its use (Bogost, 2011). In part, this view holds that gamification acts as a sort of manipulation that primarily aims to induce users to perform behaviors that they otherwise would not perform (Xu, 2011). This criticism focuses not on the mechanisms through which gamification exerts influence, but instead on the motivation and desired outcomes of the gamification architects. Gamification often includes some form of deception (Burawoy, 1979), and inherent in its use is the implication that it encourages the user to engage in behaviors desired by the designer of the context. It is clear that these desired behaviors can be positive or negative for the user. To the extent that those behaviors are detrimental or behaviors in which users would prefer not to engage (for example, pay-forplay applications), gamification may be unethical. On the other hand, gamification often has been used to motivate healthy, self-promoting and consensual behaviors, as detailed above (for example, Hamari and Koivisto, 2015b). The ethical quality of a gamification exercise can only be judged on a case-by-case basis. Before any organization or individual implements gamification elements, they should consider the ethical and moral implications of such an initiative.

Finally, some critics fear that the introduction of game-like features into non-game activities contributes to an unaccounted proliferation of surveillance systems that pose threats to privacy and democracy (Whitson, 2013). When individuals - in their roles as employees, customers or simply citizens - interact with digital systems, they are providing information about their preferences, inclinations, skill and capabilities. The deception inherent in presenting these activities as game-like may obscure the tracking processes that generate stocks of data about individual conduct and patterns of group behavior (Rossi, 2014). Concerns arise about the value of this information, access to it, and the ways in which it is used. In the case of data collection, organizations and individuals employing gamification must not only consider ethical and moral obligations, but also legal regulations on the collection and use of individual data. It is likely that the legal implications of gamification and the use of data collected therein will continue to evolve.

\section{TAKING GAMIFICATION (MORE) SERIOUSLY: PROSPECTS FOR FUTURE RESEARCH}

Despite these criticisms, gamification is generally considered a promising approach for leveraging opportunities proffered by the contemporary digital environment. Deterding (2014a, p. 306), for instance, posits that it is possible to 'establish an alternative, more 
promising framing of gamification before discourses and institutions have fully solidified'. While research has begun to unravel the impact of gamification, it is clear that a more structured approach is needed to determine the effects, implications and best practices for the use of gamification (for example, Deterding 2014b). Hamari et al. (2014), for example, lamented the over-reliance on case studies and impressionistic accounts of gamification in the research literature. Similarly, Lieberoth (2015) called for more rigor in gamification research. It is clear that a well thought-out, programmatic body of research is needed to elucidate the impact of individual game elements, their proper application, the psychological mechanisms through which they impact behavior, and the ethical and moral implications of their implementation. Such research should incorporate a strong theoretical approach, hypothesizing both direct and indirect motivational mechanisms. In doing so, this research must utilize longitudinal experimental designs and employ the correct analytic methods (for example, path analyses, linkage analysis) to identify the impact of gamification elements on macro- and micro-level variables, distal and proximal variables, and moderators of all of the implied relationships. Armstrong and Landers' (2015) work serves as an exemplar of this type of research. In their investigation, the authors adopted a framework, the TechnologyEnhanced Training Effectiveness Mode, allowing them to test individual differences in experience and attitudes toward technology, and to determine how such differences impact the relationship between game design and training effectiveness. Below, we outline several avenues of future research that we believe will advance the field and enhance our understanding of this relatively new technique; each of these should be studied using a systematic, theoretically rooted approach.

First, more work is needed to properly assess the outcomes of gamification. Despite its pervasive presence in social, academic and business practices, the extant literature has done little to parcel out the separate and combined impacts of gaming elements. Sharpening our understanding of these elements is critical to effective game design. While scholars generally agree that effective gamification architecture is not just a matter of assembling game-like features (for example, points, badges, leaderboards and so on) and providing rules for interaction (for example, turn-based moves or chance events; Paharia, 2012a; Werbach and Hunter, 2012; Seaborn and Fels, 2015), evidence-based best practice recommendations are still lacking. While some work has focused on perceptions of various elements (Hsu et al., 2013), more research is needed to move beyond affective reactions to investigate the relationships between various gaming elements and more distal outcomes (for example, learning, job performance and lifestyle changes). 
Secondly, we must gain a better appreciation of what makes people engage in gamified situations and how those elements relate to the retention of players' interest and enjoyment over time (Hamari et al., 2015). In this respect, the field of neuroscience can provide clarification regarding the chemical effects of playing games on the brain and, relatedly, on individuals' attention, memory, drives and mood. Past studies have suggested that the enjoyment of playing a game may be related to the production of serotonin, which is also involved in inhibiting actions that result in punishments (Crockett et al., 2008; Emanuele et al., 2008; Faulkner and Deakin, 2014; Sul, 2015). The compulsion to engage in gameplay has also been linked to dopamine levels (Berridge and Kringelbach, 2008; Berridge et al., 2009; Berridge, 2012; Lewis-Evans, 2013; Robinson et al., 2005), which play an important role in the formation of initiative and desire. When gameplay prompts an addictive response, it is plausible that this results from offering the appropriate inducements and signals to stimulate the production of neurotransmitters associated with sustained desire and pleasure (Rigby and Ryan, 2011). Research into the effects of games on brain chemistry may result in more fine-grained explanations of user behavior than can be provided by more traditional motivational theories (for example, Skinner's operant conditioning, Skinner, 1938; 1971; 1974; and goal-setting theory, Locke and Latham, 2002).

The relationship between internal and external sources of motivation to play games also deserves additional attention. As previously mentioned, research has shown that extrinsic rewards can have detrimental effects on motivation (Deci, 1975; Deci et al., 1999; Deci and Ryan 2000; Ryan and Deci, 2000). By understanding sources of motivation, gamification architects may be better able to align gaming elements to desired outcomes, leveraging existing intrinsic interest to create long-term user engagement and behavioral impact (Paharia, 2012b; Watson, 2014). This is especially relevant given evidence that user enjoyment and gamification utility seem to decline with use (Koivisto and Hamari, 2014). To the extent that gamification enacts an extrinsic reward system within users, it may result in short- but not long-term user motivation and engagement. Longitudinal work is needed to investigate this possibility.

Moreover, research must also focus on the types of outcomes that may result from gamification. Various authors have argued that gamification should be directed towards fostering the collaborative ethos of individuals, rather than only their competitive drive (Rimon, 2015; Fogel, 2015). Bernstein and Blunden (2015), for example, highlighted that gamification results in positive workplace effects by stimulating teamwork and a sense of peer-to-peer accountability. Still, case examples indicate that the promotion of competition 
can also motivate behavior (Kapp, 2014). More work is needed to determine whether individual, situational or design characteristics moderate the nature of this motivational dichotomy. Such work should provide guidance on how best to structure and design gamified situations to enact each type of motivational mechanism.

Other authors have highlighted the importance of designing gamification to encourage imaginative and creative solutions (Deterding et al., 2011b; Huotari and Hamari, 2012). Gamification can vary in the extent to which the gamified activities tend to induce individuals to perform highly structured and repetitive tasks or fairly explorative and unrestrained undertakings. Different design principles, however, apply to games that are intended to spur imagination and creativity, because they should create conditions that are conducive to free-form, spontaneous and unregulated playfulness (paidia, as opposed to ludus, as per Caillois, 1961). Although devising such games may present more challenges than the gamification of structured and repetitive tasks, the kind of intellectual effort that they require could lead to a better understanding of gamification and its likely consequences (see for example Deterding et al., 2011b; Huotari and Hamari, 2012).

Finally, the potential for transformative effects from the artificial intelligence (AI) that administers gaming systems should not be overlooked. AI has exhibited dramatic improvements in recent years, especially in its capacity to detect, distinguish and categorize patterns using video, audio and other sensorial data (Nilsson, 2014). AI could be leveraged to fine-tuning algorithmic capacity to process and anticipate human behavioral patterns. As gamification provides a venue for tracking humans' behavior under changing conditions, it offers the opportunity to set up a 'virtual laboratory' wherein AI can test hypotheses about humans' reactions to behavioral clues and thus produce a transformative effect in the way that AI identifies general patterns for influencing the human side of the human-computer interaction system.

\section{CONCLUSION AND RECOMMENDATIONS}

More research is needed to provide evidence-based recommendations on the design and application of gamification in various digital initiatives; however, the work that has been done points to several guidelines. First, game elements should be aligned with desired outcomes or goals (Huckabee and Bissette, 2014). Werbach and Hunter (2012) highlighted that a well-crafted game should assemble the components of a game system in an appropriate way. Building on Hunicke et al. (2004), Robson et al. (2015) emphasize the importance of distinguishing between game mechanics (that is, rules and procedures), game dynamics (that 
is, the conduct and interaction between players), and emotions (that is, the sort of emotional effects that playing a game invokes). Second, the relative difficulty level utilized should be considered; flow theory suggests that gamified contexts should be sufficiently but not overly challenging (Huckabee and Bissette, 2014). Landers and Landers (2014) recommend designing gamified scenarios to incorporate tasks that are achievable, realistic, specific and time bound. Third, gamified contexts should be properly tested before implementation to ensure they are producing their desired effects. Empirical results suggest that gamification does not always result in positive user experiences, behaviors and desired outcomes. It is imperative that gamification be implemented only after ascertaining its effects.

The increased prevalence of gamification points to its staying power. There is some evidence to suggest that gamification can bring about remarkable effects in the areas of selfimprovement (for example, Nike+, Fitbit and so on), high-end, creative jobs (for example, TopCoder, Kaggle, Stack Overflow, Wikistrat), workplace practices and education. In applying gamification, it is important to consider its ethical implications as well as to ensure its design aligns well with the desired outcomes. As digital transformations continue, our understanding of gamification and its various applications will inevitably evolve.

\section{REFERENCES}

Antin, J. and Churchill, E.F. (2011). Badges in social media: a social psychological perspective. CHI 2011 Gamification Workshop. Accessed at http://gamificationresearch.org/wp-content/uploads/2011/04/03-Antin-Churchill.pdf.

Armstrong, M.B. and Landers, R.N. (2015). Enhancing training outcomes with gamification. Poster presented at the 30th Annual Conference of the Society for Industrial and Organizational Psychology, Philadelphia, PA, April.

Bernstein, E. and Blunden, H. (2015). The sales director who turned work into a fantasy sports competition, 27 March. Accessed at https://hbr.org/2015/03/the-salesdirector-who-turned-work-into-a-fantasy-sports-competition.

Berridge, K.C. (2012). From prediction error to incentive salience: mesolimbic computation of reward motivation. European Journal of Neuroscience, 35, 1124-43.

Berridge, K.C. and Kringelbach, M.L. (2008). Affective neuroscience of pleasure: reward in humans and animals. Psychopharmacology, 199, 457-80.

Berridge, K.C., Robinson, T.E. and Aldridge, J.W. (2009). Dissecting components of reward: 'liking', 'wanting', and learning. Current Opinion in Pharmacology, 9, 65-73. 
Bogost, I. (2011). Gamification is bullshit: my position statement at the Wharton Gamification Symposium. Accessed at http://www.bogost.com/blog/gamification_is_bullshit.shtml.

Bunchball, Inc. (2012). Gamification 101: an introduction to game dynamics, 10 October. Accessed at http://www.bunchball.com/gamification101.

Burawoy, M. (1979). Manufacturing Consent: Changes in the Labor Process under Monopoly Capitalism. Chicago, IL: University of Chicago Press.

Burke, B. (2013). The gamification of business. Forbes, 21 January. Accessed at http://www.forbes.com/sites/gartnergroup/2013/01/21/the-gamificationof-business/.

Burke, B. (2014). Gartner redefines gamification. 4 April. Accessed at http://blogs.gartner.com/brian_burke/2014/04/04/gartner-redefinesgamification/.

Caillois, R. (1961). Man, Play and Games. Champaign, IL: University of Illinois Press. Caponetto, I., Earp, J. and Ott, M. (2014). Gamification and education: a literature review. In Proceedings of the 8th European Conference on Games Based Learning (ECGBL) (pp. 50-57). Berlin: Academic Conferences \& Publishing International.

Crockett, M.J., Clark, L., Tabibnia, G., Lieberman, M.D. and Robbins, T.W. (2008). Serotonin modulates behavioral reactions to unfairness. Science, 320(5884), 1739.

Crookall, D. (2010). Serious games, debriefing, and simulation/gaming as a discipline. Simulation \& Gaming, 41, 898-920.

Csikszentmihalyi, M. (2008). Flow: The Psychology of Optimal Experience. New York: HarperCollins.

Deci, E.L. (1975). Intrinsic Motivation. New York: Plenum.

Deci, E.L. and Ryan, R.M. (2000). The 'what' and 'why' of goal pursuits: human needs and the self-determination of behavior. Psychological Inquiry, 11(4), 227-68.

Deci, E.L., Koestner, R. and Ryan, R.M. (1999). A meta-analytic review of experiments examining the effects of extrinsic rewards on intrinsic motivation. Psychological Bulletin, 125(6), 627-68.

Deterding, S. (2012). Gamification: designing for motivation. Interactions, 19, 14-17.

Deterding, S. (2014a). Eudaimonic design, or: six invitations to rethink gamification. In M. Fuchs, S. Fizek, P. Ruffino and N. Schrape (eds), Rethinking Gamification (pp. 30531). Lüneburg: Meson Press. 
Deterding, S. (2014b). Gamification absolved? 5 August. Accessed at http://gamificationresearch.org/2014/08/gamification-absolved-2/.

Deterding, S., Dixon, D., Khaled, R. and Nacke, L. (2011a). Gamification: toward a definition. CHI 2011 Workshop Gamification Research Network, 7 May, Vancouver.

Deterding, S., O’Hara, K., Sicart, M., Dixon, D. and Nacke, L. (2011b). Using game design elements in non-gaming contexts. CHI 2011 Workshop Gamification Research Network, 7 May, Vancouver.

Domínguez, A., Saenz-de-Navarrete, J., de-Marcos, L., Fernández-Sanz, L., Pagés, C. and Martínez-Herráiz, J-J. (2013). Gamifying learning experiences: practical implications and outcomes. Computers \& Education, 63, 380-92.

Dong, T., Dontcheva, M., Joseph, D., Karahalios, K., Newman, M.W. and Ackerman, M.S. (2012). Discovery-based games for learning software. Proceedings of the SIGCHI Conference on Human factors in Computing Systems, Austin, Texas, 5 May.

Dorling, A. and McCaffery, F. (2012). The gamification of SPICE. Software Process Improvement and Capability Determination, 290, 295-301.

Downes-Le Guin, T., Baker, R., Mechling, J. and Ruylea, E. (2012). Myths and realities of respondent engagement in online surveys. International Journal of Market Research, 54(5), 1-21.

DuVernet, A.M. (forthcoming). Gamification at work. In S.G. Rogelberg, S. Tonidandel and K. Shockley (eds), The SAGE Encyclopedia of Industrial and Organizational Psychology, 2nd edn. Thousand Oaks, CA: Sage Publications.

DuVernet, A.M. and Popp, E. (2014). Gamification of workplace practices. The IndustrialOrganizational Psychologist, 52(1), 39-44.

Emanuele, E., Brondino, N., Bertona, M., Re, S. and Geroldi, D. (2008). Relationship between platelet serotonin content and rejections of unfair offers in the ultimatum game. Neuroscience letters, 437(2), 158-61.

Faulkner, P. and Deakin, J.W. (2014). The role of serotonin in reward, punishment and behavioural inhibition in humans: insights from studies with acute tryptophan depletion. Neuroscience \& Biobehavioral Reviews, 46, 365-78.

Fetzer, M. (2015). Serious games for talent selection and development. The IndustrialOrganizational Psychologist, 53(1), 117-25.

Fleming, N. (2012). Gamification: is it game over? BBC, 18 November. Accessed at http: / /www.bbc.com/future/story/20121204-can-gaming-transform-yourlife. 
Fogel, G. (2015). Will 80\% of gamification projects fail? Giving credit to Gartner's 2012 gamification forecast. Accessed at http://www.gameffective.com/gamificationbasics/will-80-of-gamification-projects-fail/.

Fox, J. and Bailenson, J.N. (2009). Virtual self-modelling: the effects of vicarious reinforcement and identification on exercise behaviours. Media Psychology, 12, 1-25.

Fuchs, M., Fizek, S. and Ruffino, P. (2014). Rethinking Gamification. Lüneberg: Meson Press.

Gartner, Inc. (2011). Gartner predicts over 70 percent of Global 2000 organisations will have at least one gamified application by 2014. 9 November. Accessed at http://www.gartner.com/newsroom/id/1844115.

Google (2015). Web search interest: Gamification, worldwide, 2004-present. 10 October. Accessed at http://www.google.com/trends/explore.

Greenbook (2015). GreenBook Research Industry Trends Report, 17th edn. Accessed at http: / /www.greenbook.org/grit.

Hamari, J. and Koivisto, J. (2015a). Why do people use gamification services? International Journal of Information Management, 35, 419-31.

Hamari, J. and Koivisto, J. (2015b). 'Working out for likes': an empirical study on social influence in exercise gamification. Computers in Human Behavior, 50, 333-47.

Hamari, J., Keronen, L. and Alha, K. (2015). Why do people play games? A review of studies on adoption and use. Proceedings of the 48th Hawaii International Conference on System Sciences, Kawai, 5-8 January, pp. 3559-68.

Hamari, J., Koivisto, J. and Sarsa, H. (2014). Does gamification work? - A literature review of empirical studies on gamification. Proceedings of the 47th Hawaii International Conference on System Sciences, Honolulu, HI, 6-9 January.

Handler, C. (2014). Discussant. In E. Popp (Chair), Challenges and Innovations of Using Game-like Assessments in Selection. Symposium conducted at the 29th annual meeting of the Society for Industrial and Organizational Psychology, Honolulu, HI, May.

Hershfield, H.E., Goldstein, D.G., Sharpe, W.F., Fox, J., Yeykelis, L., Carstenson, L. and Bailenson, J.N. (2011). Increasing saving behavior through age-progressed renderings of the future self. Journal of Marketing Research, 48, 23-37.

Hsu, S.H., Chang, J.W. and Lee, C.C. (2013). Designing attractive gamification features for collaborative storytelling websites. Cyberpsychology, Behavior and Social Networking, 16, 428-35. 
Huckabee, I. and Bissette, T. (2014). Learning made fun. Training Industry Magazine, Spring, pp. 32-35. Accessed at: http://www.nxtbook.com/nxtbooks/trainingindustry/tiq_2014spring/.

Hunicke, R., LeBlanc, M. and Zubek, R. (2004). MDA: a formal approach to game design and game research. Proceedings of the Challenges in Games AI Workshop, San Jose, CA, 24-5 July.

Huotari, K. and Hamari, J. (2012). Defining gamification: a service marketing perspective. Proceedings of the 16th International Academic MindTrek Conference, Tampere, Finland, 3-5 October.

Juul, J. (2011). Gamification backlash roundup. The Ludologist, 2 April. Accessed at http://www.jesperjuul.net/ludologist/gamification-backlash-roundup.

Kapp, K.M. (2014). What L\&D professionals need to know about gamification. Training Industry Magazine, Spring, pp. 16-19. Accessed at http://www.nxtbook.com/nxtbooks/trainingindustry/tiq_2014spring/.

Koivisto, J. and Hamari, J. (2014). Demographic differences in perceived benefits from gamification. Computers in Human Behavior, 35, 179-88.

Landers, R.N. and Callan, R.C. (2011). Casual social games as serious games: the psychology of gamification in undergraduate education and employee training. In M. Ma, A. Oikonomou and L.C. Jain (eds), Serious Games and Edutainment Applications (pp. 399-424). Surrey: Springer.

Landers, R.N. and Landers, A.K. (2014). An empirical test of the theory of gamified learning: the effect of leaderboards on time-on-task and academic performance. Simulation \& Gaming, 45, 769-85.

Landers, R.N., Bauer, K.N. and Callan, R.C. (2015). Gamification of task performance with leaderboards: a goal setting experiment. Computers in Human Behavior. Accessed at http://www.academia.edu/15281615/Gamification_of_task_performance_with_leader boards_A_goal_setting_experiment.

Lewis-Evans, B. (2013). Dopamine and games - liking, learning, or wanting to play? Gamasutra, 27 August. Accessed at http: / /www.gamasutra.com/blogs/BenLewisEvans/20130827/198975/Dopa mine_and_games_Liking_learning_or_wanting_to_play.php. 
Lieberoth, A. (2015). Dressing activities as a game is enough to shift motivation, 2 February. Accessed at http://gamification-research.org/2015/02/aarhus-gamificationexperiment/\#more-1082.

Locke, E.A. and Latham, G.P. (2002). Building a practically useful theory of goal setting and task motivation: a 25year odyssey. American Psychologist, 57(9), 705-17.

Lu, A.S., Baranowski, T., Thompson, D. and Buday, R. (2012). Story immersion of videogames for youth health promotion: a review of literature. Games for Health Journal, 1(1), 37-44.

Markets and Markets (2011). Gamification market worth $\$ 5.5$ billion by 2018. Accessed at http://www.marketsandmarkets.com/PressReleases/gamification.asp.

McGonigal, J. (2011). Reality is Broken: Why Games Make Us Better and How They Can Change the World. London: Penguin Press.

Meister, J. (2012). Gamification: three ways to use gaming for recruiting, training, and health and wellness. Forbes, 21 May. Accessed at http: / /www.forbes.com/sites/jeannemeister/2012/05/21/gamificationthree-ways-to-use-gaming-for-recruiting-training-and-health-amp-wellness/.

Mekler, E., Bruhlmann, F., Opwis, K. and Tuch, A.N. (2013). Disassembling gamification: the effects of points and meaning on user motivation and performance. In Proceedings of the CHI 2013 Conference: Changing Perspectives (pp. 1137-42). Paris.

Mitchell, T.R. and Daniels, D. (2003). Motivation. In W.C. Borman and D.R. Illgen (eds), Handbook of Psychology: Industrial and Organizational Psychology, Vol. 12, (pp. 225-54). New York: John Wiley \& Sons.

Muntean, C.I. (2011). Raising engagement in e-learning through gamification. Paper presented at the 6th annual International Conference on Virtual Learning, 30 May - 3 June, Kelowna, British Columbia. Accessed at http://www.icvl.eu/2011/disc/icvl/documente/pdf/met/ICVL_ModelsAndM ethodologies_paper42.pdf.

Nilsson, N.J. (2014). Principles of Artificial Intelligence. Burlington, MA: Morgan Kaufmann.

Paharia, R. (2012a). Gamification can work - just don't hire a game designer, TechCrunch, 8 December. Accessed at http://techcrunch.com/2012/12/08/bad-gamificationdesign-leads-to-failure/. 
Paharia, R. (2012b). Gamification means amplifying intrinsic value, Social Mediator, JulyAugust, 14-17.

Papastergiou, M. (2009). Exploring the potential of computer and video games for health and physical education: a literature review. Computers \& Education, 53, 603-22.

Perryer, C., Scott-Ladd, B. and Leighton, C. (2012). Gamification: implications for workplace and intrinsic motivation in the 21 st century. AFBE Journal, 5(3), 371-81.

Popescu, M., Romero, M. and Usart, M. (2012). Using serious games in adult education serious business for serious people-the MetaVals game case study. In Proceedings of 7th International Conference on Virtual Learning (pp. 125-34). Bucharest, 25 October.

Rigby, S. and Ryan, R. (2011). Glued to Games: How Video Games Draw us in and Hold us Spellbound. Santa Barbara, CA: Praeger.

Rimon, G. (2015). Team vs individual incentives? Transparency makes the difference. Accessed at http://www.gameffective.com/gamification-basics/team-vsindividual-incentives-transparency-makes-the-difference/.

Robinson, S., Sandstrom, S.M., Denenberg, V.H. and Palmiter, R.D. (2005). Distinguishing whether dopamine regulates liking, wanting, and/or learning about rewards. Behavioral Neuroscience, 119(1), 5-15.

Robson, K., Plangger, K., Kietzmann, J.H., McCarthy, I. and Pitt, L. (2015). Is it all a game? Understanding the principles of gamification. Business Horizons, 58(4), 411-20.

Rossi, B. (2014). Gamification: where did it all go wrong? Information Age. Accessed at http: / /www.informationage.com/industry/software/123458673/gamification-where-did-it-all-gowrong.

Rouse, K.E. (2013). Gamification in science education: The relationship of educational games to motivation and achievement (Doctoral dissertation). ProQuest Dissertations and Theses database (AAT 3569748).

Ryan, R. and Deci, E. (2000). Self-determination theory and the facilitation of intrinsic motivation, social development, and well-being. American Psychologist, 55, 68-78.

Seaborn, K. and Fels, D.L. (2015). Gamification in theory and action: a survey, International Journal of Human-Computer Studies, 74, 14-31.

Skinner, B.F. (1938). The Behavior of Organisms: An Experimental Analysis. New York: Appleton-Century-Crofts.

Skinner, B.F. (1971). Beyond Freedom and Dignity. New York: Springer. 
Skinner, B.F. (1974). About Behaviorism. New York: Knopf.

Staw, B.M. (1976). Knee-deep in the big muddy: a study of escalating commitment to a chosen course of action. Organizational Behavior and Human Performance, 16(1), $27-44$.

Sul, S. (2015). Determinants of Internet game addiction and therapeutic role of family leisure participation. Journal of Inclusion Phenomena and Macrocyclic Chemistry, 82(1-2), 271-8.

Sung, H-Y. and Hwang, G-J. (2013). A collaborative game-based learning approach to improving students' learning performance in science courses, Computers \& Education, 63, 43-51.

Taylor, K. (2014). Tracking trends. Training Industry Magazine, Spring, 52-3. Accessed at http://www.nxtbook.com/nxtbooks/trainingindustry/tiq_2014spring/.

Training Industry, Inc. (2015). Best practices in design and delivery of sales training programs. Accessed at http: //www.trainingindustry.com/trainingoutsourcing/products/research/best-practices-in-design-and-delivery-ofsales-training-programs.aspx.

Walz, S. and Deterding, S. (2014). The Gameful World: Approaches, Issues, Applications. Cambridge, MA: MIT Press.

Watson, Z. (2014). Why intrinsic motivation is the key to successful gamification. Accessed at http://technologyadvice.com/gamification/blog/intrinsic-motivation-buildssuccessful-games/.

Werbach, K. and Hunter, D. (2012). For the Win: How Game Thinking Can Revolutionize Your Business. Philadelphia, PA: Wharton Digital Press.

Whitson, J.R. (2013). Gaming the quantified self, Surveillance and Society, 11(1/2), 163-76.

$\mathrm{Xu}, \mathrm{Y}$. (2011). Literature review on Web application gamification and analytics. CSDL Technical Report 11-05.

Yee, N., Bailenson, J.N. and Ducheneaut, N. (2009). The Proteus effect: implications of transformed digital self-representation on online and offline behavior. Communication Research, 36(2), 285-312.

Zhu, M., Huang, Y. and Contractor, N.S. (2013). Motivations for self-assembling into project teams. Social Networks, 35(2), 251-64. 